\title{
La constitución de la identidad personal en el nuevo capitalismo y sus repercusiones morales
}

\author{
The constitution of personal identity in the new \\ capitalism and its moral implications
}

BORJA GARCÍA FERRER*

\begin{abstract}
Resumen: Con el objeto de colmar el vacío teórico y ético de los simplificadores de los «maestros de la sospecha», analizamos el devenir imagen del sistema-capital y la consiguiente supremacía del exterior, un universo inédito y peligrosamente alarmante que exige, eo ipso, repensar cuestiones como la identidad personal o el modo de vida, concebir su estatus y evaluar sus implicaciones morales en el presente, toda vez que la re-significación capitalista del espacio alcanza su eco siniestro en la temporalidad del vivir como una fuerza centrífuga, a costa del sistema de valores que había regido la existencia hasta ahora.

Palabras clave: «Capitalismo tardío», «conversión en imagen», «revolución espacial», identidad personal, estilo de vida, «Nihilismo axiológico».
\end{abstract}

\begin{abstract}
In order to fill the theoretical and ethical gap of the simplifiers of the «masters of suspicion», we analyze the capitalist system (which is becoming only an image) and the resulting supremacy of the world beyond, such an unprecedented and dangerously alarming universe that demands, eo ipso, that we rethink issues such as personal identity or lifestyle, apprehend its status and assess its moral implications in the present, given that the capitalist re-signification of space finds its sinister echo in the temporality of living as a centrifugal force, at the expense of the system of values that had ruled life so far.

Keywords: «Late Capitalism», «image-becoming», «spatial revolution», personal identity, lifestyle, «axiological Nihilism».
\end{abstract}

¿No se esconde detrás del descreído debilitamiento del hombre una estructura de dominio, no vive en y por un funcionamiento económico devorador y depredador?

F. JAMESON

Fecha de recepción: 10/06/2014. Fecha de aceptación: 06/11/2014.

* Doctorando de Filosofía en la Universidad de Granada. E-mail: borja_co@hotmail.com. Sus líneas de investigación son: Filosofía contemporánea, ontología política, sociología crítica, psicopatología. Entre sus publicaciones más recientes, destacan: «La comunidad ortopédica. Por una crítica de patologías desde el paradigma inmunológico», Isegoría. Revista de Filosofía Moral y Política, 52, 2015, pp. 331-348, y «De las máquinas totalitarias al "Capitalismo emocional". Consideraciones en torno a la impostura de la “desinhibición”», Agora: papeles de Filosofía, 34, 1, 2015, pp. 189-211. 


\section{Introducción}

Desde los primeros rumores del «Nihilismo» como el agente patógeno que nos arroja en la única dirección de la nada vacía, el pensamiento contemporáneo no ha cesado en su empeño por desvelar sus alargadas sombras, orientando el proyecto de los «maestros de la sospecha» hacia las fuerzas universales y sin rostro que condicionan subrepticiamente nuestra visión del mundo y nuestro modus vivendi. Y es que como revela el pujante malestar en la cultura y la miseria existencial por la pérdida de los fundamentos y valores que daban sentido a la vida, la experiencia de que el desierto avanza persiste e in-siste intensamente, hasta el extremo que la filosofía ha venido proclamando solemnemente, como si el metódico exterminio bajo la locura nazi tuviera continuidad, silente y cotidiano, en la reducción de lo humano a mera «existencia» (Bestand), la «muerte del sujeto»1.

Sin embargo, entendemos que la crítica filosófica ha sido desafortunada en sus conclusiones pues, a pesar de su progresiva denigración a manos de los mecanismos ciegos que lo gobiernan, el sujeto conserva su valor, o sea: «El papel del yo cambia, pero no desaparece. Pierde su naturaleza hipertrófica, pero no su ineliminable función vital» ${ }^{2}$. Con el objeto de mostrar el sentido de nuestra tesis y probar su alcance, nos proponemos revisar radicalmente, a la luz de los procesos contemporáneos, las coordenadas que habían guiado la teoría y la praxis hasta ahora [\$2], en aras de interpretar desde constructos articulados con cierto grado de certidumbre el contexto problemático donde surgen, se desarrollan y son valorados críticamente fenómenos culturales vagamente conocidos, a menudo confundidos con meras invenciones arbitrarias, pero decisivos para evaluar, en virtud de una formulación conceptual y argumentada del nuevo concepto de identidad personal y su peculiar modo de vida [\$3], el peligro que conllevan la constitución de subjetividades en nuestros tiempos de penuria, esto es, la actualidad del «Nihilismo» en su dimensión axiológica [§4].

Para ello, es de recibo realizar, en primer lugar, dos aclaraciones metodológicas. Dado que se trata de un fenómeno global, pues alcanza su eco en la nervadura que articula las prácticas colectivas, las costumbres, los hábitos y, en definitiva, nuestra vida cotidiana, nos vemos abocados a adoptar para nuestra exposición un enfoque macroscópico, entre la filosofía y la ontología política, con el objeto de abrir un horizonte interdisciplinar en el diagnóstico de patologías socio-culturales específicas que puede tener prolongaciones productivas, a nivel microfísico, en ética y estética. Por otro lado, el objetivo de nuestra investigación no es sino llevar a cabo una aportación crítica y original desde una comprensión adecuada y una asimilación creativa de la bibliografía reciente, por razón de lo cual asumimos un punto de vista ecléctico, apelando con recurrencia a perspectivas aparentemente incompatibles. No obstante, estamos convencidos que lo más interesante de la filosofía contemporánea no responde a una escuela de pensamiento en particular o la sumatoria de varias, sino en las

1 Para una panorámica general de las corrientes implicadas, nos remitimos al Proyecto de I+D «La filosofía como terapia social» a cargo del Departamento de Filosofía II de la UGR, un proyecto que aspira a diagnosticar enfermedades socio-culturales del presente desde su arraigo ontológico, rescatando de la «superfluidad» a la filosofía como crítica de la salud de una cultura. $C f$. www.ugr.es/ filosofiayterapia/.

2 Bodei, R., Destinos personales. La era de la colonización de las conciencias, Buenos Aires, El cuenco de plata, 2006, p. 449. 
singladuras, los enlaces y los hiatos entretejidos en el trayecto (pólemos) que va desde unas hacia otras, configurando un panorama reticular, osmático y multiforme.

\section{Capitalismo y espacialidad: La nueva «era de la imagen del mundo»}

En su particular empeño por ofrecer a la humanidad, erigido en el «médico de la civilización» por excelencia, un diagnóstico de su ocaso, anunciaba Nietzsche, en los albores del siglo XX, que el «Nihilismo», «el más inquietante de todos los huéspedes» ${ }^{3}$, nos acecha. No es arbitrario, en efecto, el carácter intempestivo atribuido al maestro pues, entretanto, hemos obtenido tantas pruebas de su vigencia que hablar del «Nihilismo» a la altura del presente es hacerlo, parafraseando a Heidegger, de un inquietante huésped que, como la ausencia de pensamiento, entra y sale por todas partes, saturando sin paliativos aquello que desde los orígenes del pensamiento occidental viene denominándose éthos. Tras finalizar la II Guerra Mundial, la esfera cultural mantuvo cierta autonomía, es cierto, hasta la revolución microelectrónica producida durante los cuarenta y cincuenta del pasado siglo. Desde entonces, el advenimiento de las nuevas tecnologías de la información y la comunicación (NTIC), su consolidación hacia los setenta en los Estados Unidos de América y su fulgurante difusión por la totalidad del orbe han contribuido decisivamente en la invasión imparable del ámbito de la cultura bajo el signo del Capital, como revela el incontestable triunfo del «último hombre», vaticinado lúcidamente por Nietzsche, en su actual estadio ultra-consumista.

Desde esta óptica, concediendo su parte de razón a quienes advierten el imperio de fuerzas anónimas e inconscientes en el «mundo de la vida» (Lebenswelt), consideramos que el demonio que teje nuestros destinos, por decirlo con Weber, responde eminentemente a las nuevas formas de dominio del Capital, hasta tal punto que «toda posición posmodernista en el ámbito de la cultura (ya se trate de apologías o de estigmatizaciones) es, también y al mismo tiempo, necesariamente, una toma de postura implícita o explícitamente política sobre la naturaleza del capitalismo multinacional actual» ${ }^{4}$. Somos conscientes que abrazar

3 Nietzsche, F., Fragmentos póstumos (vol. IV), Madrid, Tecnos, 2006, p. 114.

4 Jameson, F., El posmodernismo o la lógica cultural del capitalismo avanzado, Barcelona, Paidós, 1991, p. 14. El autor norteamericano ha cumplido recientemente su deseo de actualizar la célebre tesis que anuda su teoría de la Postmodernidad a través del análisis de fenómenos propiamente contemporáneos, haciendo gala de su habitual perspicacia: $c f$. Jameson, F., El postmodernismo revisado, Madrid, Abada, 2012. Por lo demás, la relación entre Capitalismo y «Nihilismo» ha sido explorada profusamente por la moderna bibliografía, al hilo de la impresionante escalada de fenómenos mórbidos en los últimos tiempos. Muchos hacen hincapié en la relación entre nuevas patologías y la crítica del poder. Por ejemplo, A. Rico postula una antropología del mercado y analiza ese fin del neolítico donde el Capitalismo nos precipita hasta arrojarnos a una sociedad que sólo depende de la supervivencia, donde la «liberalización del hambre», la «privatización de la mirada» y la «miseria simbólica» borra las diferencias y difumina los límites, a costa de la experiencia, la responsabilidad y la comunidad: $c f$. Alba, S., Capitalismo y Nihilismo. Dialéctica del hambre y la mirada, Madrid, Akal, 2007. Boltanski y Chiapello denuncian con copiosa información el nuevo espíritu del Capital, creador de ficciones de autonomía que nos convierten, manipulando los afectos, en «operadores» activos, «catalizadores» o «inspiradores»: cf. Boltanski, L. y Chiapello, E., El nuevo espíritu del capitalismo, Madrid, Akal, 2002. Análogamente, Sennett emprende una severa reflexión ética sobre la nueva concepción del trabajo de transitoriedad, innovación y proyectos a corto plazo, en detrimento de las nociones de permanencia, confianza, integridad y compromiso que habían articulado nuestras vidas en el marco de la comunidad: $c f$. Sennett, R., $L a$ corrosión del carácter. Las consecuencias personales del trabajo en el nuevo capitalismo, Barcelona, Anagrama, 2000. Entre la filosofía y la psicología médica, F. Alonso-Fernández describe cómo la actividad laboral 
una hipótesis de periodización histórica en nuestro presente representa, cuando la propia noción de período histórico es ya problemática, una empresa controvertida. Sin embargo, pensamos que todo análisis cultural implica una teoría soterrada de periodización histórica, por lo que nos sentimos obligados a señalar algunas observaciones esenciales donde cabría desarrollar, sin duda, una discusión más dilatada.

Cuando señalamos el Capitalismo como leitmotiv de nuestra época desde la óptica de los «maestros de la sospecha», no estamos aludiendo al estado de cosas denunciado por Marx sino que pensamos, como indican las premisas más elementales de su materialismo histórico, en la transformación experimentada en el transcurso de los noventa y el nuevo milenio, esto es, la llamada «Postmodernidad consumista». Nuestra hipótesis de periodización histórica no designa, empero, una homogeneidad compacta, sino que el desarrollo del modo de producción capitalista despliega, por así decirlo, la lógica hegeliana, a saber, superar conser$v a n d o^{5}$. De hecho, el «Capitalismo avanzado» no sólo no ha renunciado al pre-capitalismo (todavía existen condiciones de esclavitud dolorosamente física), sino que lo fabril y el campo persisten en el nuevo paradigma inmaterial del trabajo (conviviendo la precarización más extrema con los siervos de la gleba), mientras que el proceso acumulativo no radica exclusivamente en el trabajo «común» (Negri) sino también en el individuo, según la tesis ricardiana-marxista. Ahora bien, la nueva formación social no remite, contra la ortodoxia marxista, a los principios del Capitalismo clásico (ubicuidad de la lucha dialéctica entre clases y preeminencia de la producción industrial), sino a dinámicas que conceden un carácter original a su actual estadio en perspectiva histórica. En efecto, la hazaña del «Capitalismo posindustrial» es prolongar su dictadura desde el tiempo de producción a la circulación del capital, extrayendo nuevas plusvalías del cuerpo social hasta elevar la mercancía a la categoría de límite ontológico, en lo que constituye la consumación capitalista del mundo.

En este contexto, las NTIC desplazan a la «disciplina de fábrica» y la «cadena de montaje» como instrumentos privilegiados del poder, de tal suerte que la «hiperestimulación semiótica» se erige, en su condición de «deshinibidor pulsional», como arma estratégica por excelencia para determinarnos, saturando nuestra atención, en una especie de encantamiento hipnótico, mediante la profusión lujuriosa de reclamos publicitarios, eventos, product placement, etc. ${ }^{6}$. Mientras la nueva investigación de mercados agudiza su ingenio, al hilo de las jugosas averiguaciones del neuromarketing sobre nuestro sistema emocional, en su afán

(trabajo personalizado, violencia, desempleo, ocupación del tiempo libre,...) puede conducirnos al malestar o la enfermedad (alienación, depresión, estrés,...): cf. Alonso-Fernández, F., ¿Por qué trabajamos?, Madrid, Díaz de Santos, 2008. Tales estudios han propiciado programas teórico-prácticos de orientación terapéutica. Así, Stiegler señala que la promoción del «valor espíritu» frente al «populismo industrial», desindividuante o proletarizador, se apoya en la dualidad potencialmente terapéutica de los dispositivos técnicos, a saber, los nuevos pharmaka del Capitalismo hiperindustrializado: $c f$. Stiegler, B., Réenchanter le monde. Le valeur esprit contre le populisme industriel, Paris, Flammarion, 2006; Prendre soin. De la jeunesse et des générations, Paris, Flammario, 2008.

$5 C f$. Díaz, J., «"Planet terror”: Esbozo para una tanatopolítica», en: S. Arribas y otros (eds.): Hacer vivir, dejar morir. Biopolítica y capitalismo, Madrid, Arbor, 2010, pp. 223-45, pp. 241-3.

6 Hemos indagado en un estudio preliminar, bajo la luz arrojada por la imagen científico-técnica del mundo en Heidegger, el perfil y las consecuencias de semejante dispositivo a nivel ontológico, adoptando un enfoque interdisciplinar para determinar, en términos de «desarraigo» y «errancia», sus expresiones morbosas de superficie. Cf. García, B., «Tiempos de penuria: el "bombardeo semiótico" o la conquista del espacio interior», Otros logos. Revista de Estudios Críticos, 4, 2013, pp. 39-63. 
por seducirnos por vías impensables para la teoría económica tradicional (tacto, olfato,...) la palabra y la imagen siguen protagonizando la histeria comunicativa en curso, aunque el progreso tecnológico ha venido otorgando durante las últimas décadas soportes autónomos a la imagen muy técnicos y estratégicos, mecanismos de persuasión y control en virtud de los cuales aventaja a la escritura en el punto de moldear nuestra forma de pensar y valorar ${ }^{8}$. De manera que el Capital logra culminar universalmente, más allá de las prácticas apostólicas de difusión que, consideradas desde la inmanencia histórico-eclesiástica, podrían concebirse como la prosecución del milagro de Pentecostés por medios gutenbergerianos, la aspiración moderna de construir un imperio de mensajes, cuyos ecos sobrepasan, literalmente, el nivel capilar; Sloterdijk no puede mostrarse más revelador al respecto: «Hollywood, la metrópolis pacífica de las imágenes, ha quitado la primacía a las centrales emisoras mediterráneas para morales y misterios, Roma y Jerusalén, desde hace medio siglo. Sus mensajes no se dirigen, desde luego, a las culturas pequeñas, cuyos mercados son demasiado estrechos para los productos del nuevo imperialismo amusant. Aunque ya prometen las ganancias más lucrativas si consiguen promocionarse en dos docenas de versiones sincronizadas»9.

A decir verdad, la imagen nos ha dominado desde siempre, a pesar de ocupar un lugar subordinado en el léxico filosófico. Sin embargo, no existe la imagen en sí misma, ya que las revoluciones técnicas varían su estatuto y sus poderes constantemente, de forma que nuestros ojos tienen una historia y, cada era, su inconsciente óptico ${ }^{10}$. Pues bien, lo que marca la diferencia en el «Capitalismo tardío» es que, como bien saben los agentes del moderno sector de la cultura, esos dioses menores de la publicidad y del marketing, la imagen representa, junto al «dinero» o la «mercancía», un concepto rector imprescindible, hasta el prurito que la ciencia de la imagen o «imagología» ${ }^{11}$ se adueña de todos los escenarios, articulando

7 Aunque se trata de una disciplina incipiente, la aplicación de las técnicas de neuroimagen a la ciencia del marketing ha levantado grandes expectativas en el mundo académico y empresarial, en la medida que permiten averiguar la conducta de los consumidores en términos de activación cerebral, sin necesidad de atender a su experiencia consciente. El siguiente estudio analiza las diversas aproximaciones teóricas y metodológicas al neuromarketing con vistas a diseñar estrategias comerciales: Burgos, A., y Vargas, J., «Analitical Approach to Neuromarketing as a Business Strategy», Procedia - Social and Behavioral Sciences, 99, 2013, pp. 517-25. Para indagar las tecnologías y métodos que emplea actualmente, véase: Sebastian, V., «Neuromarketing and Evaluation of Cognitive and Emotional Responses of Consumers to Marketing Stimuli», Procedia - Social and Behavioral Sciences, 127, 2014, pp. 753-7.

$8 C f$. Rubio, J. M., «Filosofía y medios de la comunicación. Más allá de la información», en: R. Ávila y otros (eds.): Itinerarios del nihilismo. La nada como horizonte, Madrid, Arena Libros, 2009, pp. 303-19, p. 307. Mención especial merece, en esta línea, la obra de Baitello, empeñado en denunciar los perversos efectos antropológicos de lo que él mismo ha denominado «era de la iconofagia» en favor del mercado, toda vez que «devorar imágenes» o «ser devorados por ellas» no son opciones alternativas, sino simultáneas. Pues la proliferación indiscriminada de imágenes no solo coloniza nuestro imaginario, vertebrando oscuramente nuestra memoria colectiva. Además, petrifica la vida en símbolos matemáticos y categorías abstractas, signos y símbolos que abocan inexorablemente a la inercia, la indiferencia y la muerte. $C f$. Baitello, N., La era de la iconofagia, Sevilla, Arcibel, 2010.

9 Sloterdijk, P., En el mundo interior del capital. Para una teoría filosófica de la globalización, Madrid, Siruela, 2007 , p. 164.

10 Debray explora la evolución de nuestra mirada, desde las cavernas ornamentadas pictóricamente hasta la pantalla del computador, para concluir que el mito de la «civilización de la imagen» no es sino un leve inciso entre la era de los ídolos y de lo visual, donde presuntamente estamos entrando. $C f$. Debray, R., Vida y muerte de la imagen: historia de la mirada en Occidente, Barcelona, Paidós, 2002.

11 Cf. Kundera, M., La inmortalidad, Barcelona, Tusquets, 1997, pp. 89-92. 
la llamada «sociedad del espectáculo». Se trata del espectáculo como «vida en la imagen» (Debord), una imagen disociada de la gravedad del mundo, pues no sólo lo representa, como observa Heidegger en su mordaz crítica de la Modernidad, sino que lo borra y trasciende ocupando, a modo de simulación efectiva o «simulacro» (Baudrillard), su lugar ${ }^{12}$.

Así pensadas, la función mediadora del sistema de los objetos (producidos como mercancías fetichizadas y elevados a la «forma-valor») no agota ya el protagonismo de las imágenes, pues han llegado a constituirse como sus propios emisarios o, como dice Jameson, las «mercancías de nuestro tiempo». Digamos que las proyecciones del deseo saturan el mundo de tal manera que, para satisfacerlo, las mercancías han renunciado a cristalizarse en objetos para asumir la materia intangible de los sueños y trocarse imágenes. En el contexto de la inmaterialidad absoluta, los deseos lo tienen fácil para abrazar los productos tocados por el Capital, pues habitan ya «un mundo poblado de infinitos conos escópicos, que salen de cada lugar y se dirigen hacia cualquier otro, en cualquier dirección, como si en todas ellas presumieran (...) un captor, un (digamos) "espectador", un operador de recepción (una pantalla) (...) interceptando su viaje (...) para escuchar el testimonio que (...) tienen que decir» ${ }^{13}$.

Por tanto, tenemos que en la nueva «era de la imagen del mundo», los deseos errantes son interpelados por la movilidad inconsistente de las «imágenes-mercancías», esas «últimas cosas», para ser deglutidas con profusión, mientras que la erección de la «forma-mercancía» en principio trascendental se trata, paradójicamente, de un proceso de «des-ontologización», por concurso del cual habitamos un espacio sin «sí-mismo» donde nada es porque caduca, se consuma y desecha, según el arbitrario precepto de «usar y tirar». Se trata, efectivamente, de «un desfile en el que las cosas ya no son objetos estables que configuran un mundo, sino un escaparate en renovado movimiento en el que los objetos desaparecen antes de empezar a usarse; en tales condiciones, la consistencia ontológica del mundo se torna inviable, (...) las cosas no arraigan, no sedimentan, no articulan, no configuran, los hombres no pueden tejer alrededor de ellas hilos de consistencia cultural y simbólica» ${ }^{14}$.

No nos pasa desapercibido que el principio de «destrucción creadora» ${ }^{15}$ constituye el dato de hecho esencial del Capitalismo, de tal manera que el nuevo estado de cosas que acabamos de bosquejar no sería, bajo miradas escépticas, sino un recambio cuantitativo de lo mismo. Sin embargo, la novedad estriba, como queda dicho, en que la oferta de operadores de seducción ha crecido tanto para satisfacer la demanda ilimitada de deseo que abarcan todo el «ahí» donde nos encontramos sumergidos, estableciendo una «revolución cartográfica» sin parangón. En efecto, el Capital lleva la exterioridad reticulada, grabada por los comunes denominadores del dinero y la geometría, a todas partes, arrancando los deseos que crecen por sí mismos para enclavarlos en la reja de la red. Como resultado: «Los seres humanos

12 Cf. Debord, G., La sociedad del espectáculo, Valencia, Pre-Textos, 1999. Cf. Baudrillard, J., Il patto di lucidità o l'intelligenza del male, Milán, Rafaello Cortina, 2006.

13 Brea, J. L., «La era de la imagen electrónica», Contrastes. Revista Internacional de Filosofía, 17, 2012 , pp. $15-28$, p. 15.

14 Polo, J., «Postmodernidad consumista y Nihilismo de la mercancía», Éndoxa: Series Filosóficas, 23, 2009, pp. 309-57, p. 319.

15 Schumpeter lo formula del siguiente modo: «El proceso de mutación industrial (si se me permite usar esta expresión biológica) que revoluciona incesantemente la estructura económica desde dentro, destruyendo ininterrumpidamente lo antiguo y creando continuamente elementos nuevos». Schumpeter, J. A., Capitalismo, socialismo y democracia, Barcelona, Folio, 1984, p. 121. 
ya no pueden permanecer (...) en sus tradicionales espacios interiores de mundo y en sus fantasmáticas dilataciones y redondeos. (...) En tanto que participan del gran cambio, (...) han dejado (...) sus tiendas celestes, montadas y asentadas terrenamente, para moverse ya para siempre en un exterior insuperable, (...) cada día más organizado, en el que convergen la política social y la arquitectura de interiores» ${ }^{16}$.

\section{El nuevo concepto de identidad personal en la vida del mercado}

Aplicado a la idea de lugar como telón de fondo para cosas y seres, la «revolución permanente» del mercado no sólo contamina ese trasfondo sino también, y no en último término, las formas de vida desplegadas en su decurso, de manera tal que descoloca y dispersa la existencia análogamente a la diáspora judía de los dos últimos milenios, más allá de la desestructuración vital desencadenada por la industrialización decimonónica según los maestros de la sociología (Durkheim, Simmel, Tönnies,... $)^{17}$. Por efecto de la progresiva lejanía del «nosotros» y del relativo desfallecimiento de nuestros vínculos con las cosas, no podemos considerarnos, frente a los sectores integrados de la Posmodernidad consumista, como «centros soberanos» desplegados por cualidades vividas bajo el cielo que nos ha visto nacer pues, instalados a la intemperie del nuevo paisaje constituido, según la metáfora de Bauman, por el elemento líquido, vagamos erráticamente ${ }^{18}$ por sus desiertos de agua como embrutecidos psicóticos de expedición; en este sentido, Sloterdijk no sólo expresa como nadie el carácter patético de nuestra existencia, sino que también nos advierte sobre sus nefastas consecuencias: «Están diseminados fuera (...) como cuerpos locos en un espacio deshabitado. (...) Viven (...) de los ardores de la fricción que les provoca su arrojo hacia delante. (...) Dan la impresión de proyectiles que han abandonado todos los dispositivos fijadores, con el fin de moverse en una no-proximidad y no-esfera generales, en un mundo

16 Sloterdijk, P., op. cit., p. 45.

17 De aquí la crisis irreversible del legado más efectivo de la era sedentaria (desde el patriotismo agrario de las culturas arcaicas, articulado por la ambivalencia funeraria y alimenticia de la tierra, hasta la «defensa de la patria» como uso legítimo de la violencia en la Modernidad), a saber, la territorial fallacy que deriva el sentido de la vida del territorio donde transcurre, equiparando espacio y sí-mismo. Frente a la falacia originaria de la razón territorializada, las condiciones político-culturales de residencia ya no estriban en la estructura inmunológica, real e imaginaria, vivida como «identidad regional» pues, como ilustra el judaísmo durante su exilio, los grupos «desterritorializados» no construyen su inmunidad simbólica y su coherencia étnica sobre un suelo fundamentador, sino que su intercomunicación funge directamente como un «recipiente autógeno» (la Torá, en el caso judío) donde los individuos se mantienen «en forma» mientras el grupo discurre por paisajes externos. $C f$. Sloterdijk, P., «Patria y globalización: Notas sobre un recipiente hecho pedazos», Observaciones Filosóficas [www.observacionesfilosoficas.net/patriayglobal.html]. Como consecuencia, asistimos a un florecimiento de fenómenos de desarraigo sin precedentes. En debate con la Teoría Crítica frankfurtiana, el autor alemán examina el espíritu falto o apartado del mundo movido por una preocupación terapéutica, materializada en una «psicosomática» que analiza procesos de una actitud objetivante frente al mundo y expone la necesidad perentoria de experimentar nuevamente la proximidad con lo terrenal y los modos de vida. $C f$. Sloterdijk, P., Zorn und Zeit. Politisch-psychologischer Versuch, Frankfurt am Main, Suhrkamp, 2006.

18 Entendemos la «errancia» en su origen latino (erraticus), como «carecer de lugar» y «recorrer a la ventura». En concreto, la RAE le atribuye los siguientes significados: 1. «Vagabundo, ambulante, sin domicilio cierto». 2. «Errante», en cuanto estrella errante o planeta $(\pi \lambda \alpha v \eta \dot{\tau} \eta \varsigma)$. 3. En medicina, el término hace referencia a un dolor «crónico», que oscila por el cuerpo sin asiento fijo. Cf. Sáez, L., Ser errático. Una ontología crítica de la sociedad, Madrid, Trotta, 2009, p. 135. 
exterior, liso e indiferente de recursos, dirigido sólo por órdenes y apetitos y mantenido en forma por crueldad-fitness. Sus cuerpos (...) son los "termómetros de un devenir" en dirección a situaciones de desterritorialización moral jamás vividas» ${ }^{19}$.

Con la generalización de una existencia apátrida vagando, parafraseando a Sloterdijk, por los «centros sin núcleo» y las «periferias híbridas» del hipermercado social, se imponen paroxísticamente las melancólicas reflexiones de los observadores del tiempo (Baudelaire, Benjamin,...) sobre el creciente protagonismo de la «forma-mercancía» en la transformación técnica y monetaria del mundo, el enfriamiento generalizado de las cosas y su raquítico aspecto de maqueta y esqueleto ${ }^{20}$. Desde entonces, las cosas ya no pertenecen, reducidas a meras mercancías, a un sólo propietario orgánico, sino que discurren ambiciosamente entre las personas, como poseídas por una impulso maligno encaminado a traicionar la lealtad. El mérito de Benjamin es extrapolar, desde esta perspectiva, la lógica de la infidelidad de las propiedades materiales a los atributos personales, toda vez reducidos al puro «valor de uso»; en este sentido, «la conclusión lógica de la sociedad de mercado es la prostitución generalizada, la transformación del género humano en proveedores o clientes, en un ejército de manos que prodigan múltiples cuidados a pudientes apresurados» $»^{21}$.

Pero a pesar de la extraordinaria sensibilidad que atesora, Benjamin no llegó a percibir el devenir patológico de su diagnóstico, un alcance anticipado por la hipérbole crítico-cultural de Ortega sobre el ocaso de los valores y la desorientación vital, pero cuya vigencia sólo resulta inteligible si contemplamos los devaneos de la identidad personal a la vista de la nueva supremacía del exterior, esto es, del desencantamiento de las cavidades locales de inmunidad y su correspondiente «nomadización»(Aufent-haltslosigkeit). Y es que con los entrañables claustros maternos de la «patria» (Heimat) en la latencia, estamos constreñidos a relacionarnos continuamente con dimensiones extrañas, transitorias y precarias, en lo que constituye una revolución antropológica sin equivalentes históricos ${ }^{22}$. De manera que nuestro modo de vida experimenta inevitablemente un giro radical, aunque rutinario, desde la «pertenencia» (vínculos «adscriptivos») hacia las «opciones» (vínculos «electivos»), un tránsito que apunta allende un mero cambio de mentalidad, ya que transforma irrevocablemente el sentido de la identidad personal ${ }^{23}$.

19 Sloterdijk, P., En el mundo..., op. cit., pp. 136-7.

20 Cf. ib., pp. 248-9.

21 Bruckner, P., Miseria de la prosperidad. La religión del mercado y sus enemigos, Barcelona, Tusquets, p. 143.

22 La paleontología demuestra que los cerebros convencionales son sistemas ahorrativos de ideas que adoptan actitudes defensivas frente a toda nueva-experiencia inesperada. De aquí su predilección por el nivel homeostático más próximo (experimentado como auto-satisfacción, confortable y conservador), hasta el punto que reaccionamos creativamente para evitar cambios de nuestro auto-estado en casos de necesidad. Pues bien, la mutación decisiva de nuestros días se cifra, al contrario, en la celebración integral de las futuras informaciones por parte de los cerebros. Por su parte, Sloterdijk extrae las consecuencias sociológicas de semejante giro cuando observa el desarrollo de nuevos caracteres sociales que poseen una gran flexibilidad, en relación con la capacidad de fingir aceptación del programa global del aprendizaje sine die. Cf. Sloterdijk, P., «Actio in distans. Sobre los modos de formación teleracional del mundo», Nómadas, 28, 2008, pp. 22-33, p. 31.

23 En contraste con las circunstancias pre-monetarias, donde la pertenencia era el precio del mundo, la característica psicosocial del éxito exige vencer la nostalgia residual por la dimensión metafísica de la Heimat y situar nuestras pertenencias en el trasfondo para adherirnos a direcciones abiertas mediante actos del comprar-se, al hilo del papel decisivo de la innovación para cumplir nuestros sueños y ser felices. Ahora bien, ante el progresivo desmoronamiento del Welfare State, cada vez más loosers recurren a privilegios 
Ciertamente, con el triunfo de la «innovación» sobre la «repetición», el sujeto no puede entenderse, en contraste con la consistencia ontológica de la personal identity moderna, como un dato originario, central y coherente, sino que designa, en palabras de Espósito, un «afuera llevado adentro» o un «adentro que se asoma afuera», es decir, un constructo operativo funcional a las condiciones existenciales impuestas por el «Tardocapitalismo»: la movilidad discontinua y la incertidumbre estructural24; así entendido, «no fue un filósofo quien consiguió formular el auténtico concepto de las ambiciones del sujeto en la era de la movilización, sino un novelista: Julio Verne, quién en el lema de su capitán Nemo, MOBILI IN MOBILI, había encontrado la fórmula de la época» ${ }^{25}$. En efecto, la divisa del autor pone de manifiesto diáfanamente nuestro sino particular en pos de realizarnos, a saber, un trabajo sisífico que jamás se traduce en nada, una licuefacción trashumante que rechaza por principio todo signo de estabilidad. Se trata, como apunta Lipovetsky, de «la vida sin imperativo categórico, la vida kit modulada en función de las motivaciones individuales, la vida flexible en la era de las combinaciones, de las opciones, de las fórmulas independientes que una oferta ilimitada hace posible» ${ }^{26}$. La «revolución espacial» del mercado ofrece, no obstante, un amplio abanico de espacios-oportunidades para ese «yo» nómada, lábil y flexible que lubrica, en un sempiterno gerundio reestructurador, la vorágine centrífuga del ciclo de renovación implementado, desde los laboratorios del marketing, por el gigantesco aparato publicitario concomitante.

En tal coyuntura, el campo semántico de la identidad subjetiva gira en torno a categorías impensables para la tradición metafísica (meccano, feuillettage, patchwork,...), toda vez que la hibridez disolvente se constituye como rasgo esencial. En su empeño sutilmente angustiado por cumplir los deseos inducidos, la personalidad contemporánea puede definirse, de hecho, como un compendio disgregado de jirones reciclables y provisionales, cuya vertebración no obedece al ideal de una «vida examinada» desde un código ético personal estable sino, al contrario, a una inquietud tan caprichosa como morbosa por experimentar una multiplicidad incoherente de «vidas paralelas» sin necesidad de asumir

gratuitos (sentimiento religioso, identidad nacional, etc.), por lo que la cuestión de la pertenencia se postula como un problema crucial del futuro. $C f$. Sloterdijk, P., En el mundo..., op. cit., p. 250.

24 En aras de expresar el estado fluido y volátil de nuestra sociedad, Bauman define la Modernidad en términos de licuefacción, de tal suerte que la flexibilidad se constituye como el atributo antropológico por antonomasia. Se trata, en realidad, de un mismo principio moderno de pleno derecho, cuya potenciación cuantitativa ha desembocado, desde la vocación irreductible por destruir y reconstruir que inaugura el pasaje a la «mayoría de edad» ilustrada, en una transformación cualitativa del proceso de modernización, en nombre del Capitalismo avanzado y consumista. En la actualidad, la disolución del individuo estriba en un sistema devorador, en la medida que nos somete a unas condiciones económicas grabadas por el imperativo de la velocidad y la desaparición, hasta el prurito que debemos planificar nuestra identidad, más allá de cualquier intervención plástica reparadora, momento tras momento. Efectivamente, la constante aceleración consumista genera sujetos «líquidos», descentrados y difusos, una nueva conciencia grabada por la disponibilidad y el reciclaje, la indeterminación y la fluctuación, la precariedad y la incertidumbre. Cf. Polo, J., op. cit., pp. 318-26. En una serie de entrevistas realizadas por el prestigioso periodista italiano B. Vecchi, Bauman describe los cambios producidos en la noción de «identidad» desde un punto de vista histórico, mostrando de forma documentada su carácter ambiguo: $c f$. Bauman, Z., Identidad, Madrid, Losada, 2005.

25 Sloterdijk, P., En el mundo..., op. cit., pp. 115-6.

26 Lipovetsky, G., La era del vacío. Ensayos sobre el individualismo contemporáneo, Barcelona, Anagrama, 1990, p. 17. 
responsabilidades y hacer balance, de manera que convierte la pluralidad de «esferas de pertenencia», a pesar de Simmel, en una fiesta fractal y orgiástica de posibilidades ${ }^{27}$.

Por oposición al modelo humanista de educación, basado en formas ejemplares de existencia y la inercia de la costumbre (moralitas) con tal de mejorar la humanidad: «Desde la perspectiva de este nuevo modelo de excelencia, la permanencia y sobre todo la permanencia de uno mismo o la adhesión duradera a unos "valores" son criticables como rigidez incongruente, incluso patológica y, dependiendo del contexto, como ineficacia, mala educación, intolerancia o incapacidad de comunicación ${ }^{28}$. En este sentido, el gusto contemporáneo por la degustación, la fluidificación de criterios y modelos y, sistemáticamente, la contingencia de nuestro «ser-ahí» y «ser-así» en la praxis histórico-vital respaldan, a pesar de los cultos New Age que trivializan esporádicamente la idea gnóstica de un «Yo ontológico» por descubrir, la condición paradigmática del «ironista liberal» (Rorty), en la medida que renuncia, instalado en la radical pluralidad, a escribir todos los aspectos de su vida en un mismo léxico, despojando de solemnidad incólume su ideario para ubicarlo, a tenor del carácter eventual de sus creencias, en un contexto socio-cultural restringido ${ }^{29}$.

\section{Las implicaciones patológicas del «Nihilismo axiológico»}

Asistimos, vistas las cosas así, a un terreno especialmente fértil para llevar a cabo, en debate con el aparato psicológico-psiquiátrico, la función terapéutica de la filosofía, puesto que un sistema axiológico sólido es conditio sine qua non para transitar por la vida con un mínimo de equilibrio y salud mental. El correlato patológico más común del presente se cifra, bajo nuestro punto de vista, en el «trastorno de personalidad múltiple», tal y como aparece reflejado en el pasaje de san Marcos (5, 1-3) donde advierte, en relación a los espíritus que lo poseen: «Mi nombre es legión, porque soy muchos» ${ }^{30}$. Como sabemos por médecins philosophes como Ribot, Janet y Binet, todo «yo» comprende una jerarquía psíquica donde múltiples «yoes» son coordinados por un «yo» hegemónico. Cuando se muestra incapaz de regular ciertos niveles de complejidad, la voluntad se pliega al acoso ejercido por una pluralidad de deseos contrastantes y la personalidad se divide en entidades independientes (en términos de Locke, cada «hombre» permanece siendo el mismo, pero en diferentes «personas»), de tal suerte que la identidad se trueca en una máquina esquizofrénica de identidades arbitrarias, y la multiplicidad de polos de conciencia, que significaba un amplio espectro

27 Se trata de una «banalización» (Verbiederung) de la antinomia básica de la vida pensada modernamente como proceso de creación ininterrumpida donde todo resultado parmenídeo que inevitablemente expresa (hablando hegelianamente, los elementos del «espíritu objetivo») nos interpela a su constante rebasamiento, en cuanto que el torrente vital es un «valor absoluto» (Nietzsche) y, por consiguiente, no puede contenerse en objetos concretos. En efecto, exonera al devenir del carácter trágico que determina su tensión con las formas, anteponiendo la mera «existencia» (Erfhärung) al principio de «autotranscendencia» (Selbstranszendenz) o «autorrebasamiento de sí» (Sich-Selbst-Ueberschtreiten) de la vida viva, o sea, la intimidad de la vivencia (Erlebnis) en su anhelo por ser más-que-vida (Mehr-Als-Leben) y escapar a la infertilidad de la objetividad, fragmentaria y limitada. Cf. Simmel, G., Intuición de la vida. Cuatro capítulos de metafísica, Buenos Aires, Nova, 1950, p. 32.

28 Boltanski, L. y Chiapello, E., op. cit., p. 584.

29 Cf. Rorty, R., Contingencia, ironía y solidaridad, Barcelona, Paidós, 1991, p. 18.

30 Bodei, R., op. cit., p. 123. Para conocer el recorrido histórico del tratamiento aplicado sobre el fenómeno del «yo múltiple» en el plano patológico: $c f$. ib., pp. 123-7. 
de posibilidades en un gobierno de coalición psíquica, en un factor de disgregación ${ }^{31}$. Pues bien, a nuestro juicio, la multiplicación de personalidades copresentes o alternantes (no sólo des-coordinadas, sino in-coordinables) en el mismo individuo ha rebasado ya la esfera individual, dado que el Capital expande la sombra de la decadencia (entendida como irresolución y desorientación) sobre nuestro éthos, allende la lógica oposicional ilustrada «normal-patológico», como una gran opacidad de aceite, hasta tal extremo que hablar del «alma dividida» es hacerlo del fenómeno contemporáneo más cotidiano ${ }^{32}$.

En tal disposición de los términos, el individuo se sumerge en el mar de la inmanencia para consagrar visceralmente, bajo la égida de los efectistas consultores, motivadores y demás seductores ocultos en los mercados de pertenencia, la realidad externa. Sin embargo, es arrastrado por las corrientes de las continuas transformaciones hasta las aguas heladas de la indiferencia moral, al precio de las expectativas colectivas más nobles ${ }^{33}$. Pues su radical disposición a dejarse llevar por comportamientos miméticos ante el ambiente social

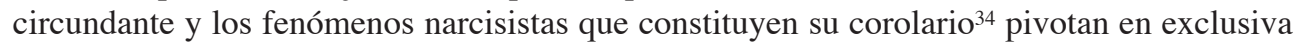
sobre mutaciones blandas de las pasiones adquisitivas en el sistema de preferencias indi-

31 Cf.ib., pp. 119-23.

32 Cf. Anders, G., La obsolescencia del hombre (vol. 1). Sobre el alma en la época de la segunda revolución industrial, Valencia, Pre-Textos, 2011, p. 142. Así entendida, la «esquizofrenia» se traduce en la ociosa tendencia a dedicarnos a diversas actividades al mismo tiempo que llamamos «hiperactividad», como ilustra la figura del jugador pasivo simultáneo y del hiperactivo que no hace nada. Sirva como botón de muestra «el hombre en el solario, que tuesta su espalda, mientras sus ojos nadan por una revista ilustrada, sus oídos están atentos a una competición deportiva y sus mandíbulas mascan un chicle». $I b$. En realidad, si su alma no se ocupa propiamente de nada es porque no es el sujeto de la ocupación, en la medida que determina la desorganización radical de su identidad, dispersa en una pluralidad de funciones cuya independización es el analogon psíquico del tumor considerado como enfermedad sui generis, esto es, cuando la fuerza central del organismo es incapaz de dominar todas las células y se multiplican autónomamente.

33 Huelga indicar que nos referimos al individuo burgués postmoderno pues, mientras los ciudadanos de Occidente consuman su disolución en la ajetreada vida del mercado, si lanzamos una mirada a la periferia nos encontramos inmediatamente con individuos que ni siquiera llegan a ser reconocidos como tales sino, más bien, como «población superflua», en lo que constituye una consecuencia inevitable de la globalización. Cf. Bauman, Z., La Modernidad y sus parias, Barcelona, Paidós, 2005. Quizás, el ejemplo más ilustrativo al respecto se cifra en la madrugada del 25 de diciembre de 1996, con el mayor naufragio de la historia de Europa tras la II Guerra Mundial. Mientras los parientes de los 283 inmigrantes ahogados frente a la costa siciliana se afanaban en sus dolorosas pesquisas, el gobierno italiano retrasaba, obstaculizaba y, finalmente, abandonaba la investigación, y los medios de comunicación ocultaban la tragedia, convertida en un accidente natural e invisible, un «no-suceso». Posteriormente, los pescadores de Portopalo, un pueblo costero de Sicilia, sacaban cadáveres en sus redes durante meses y, tras separarlos de los sargos y rodaballos, los devolvían al mar junto a la basura en un pacto de silencio, presionados por la ley del mercado y la competencia japonesa. $C f$. Alba, S., op. cit., pp. 5-8.

34 La diligencia reproductiva del narcicismo fue prefigurada con clarividencia por el análisis existencial del «ser-ahí» (Da-sein) cotidiano, en el fragmento dedicado a la «ambigüedad» y la evanescencia del estar sobre el «rastro». Cf. Heidegger, M., Ser y Tiempo, Madrid, Trotta, 2012, pp. 191-3. En esta línea, la filosofía contemporánea describe con elocuencia las «presentaciones del yo» o sus looks en la «sociedad de consumo» como la sistematización orgánica, estática pero fugaz, de una auto-ex-posición revestida de patetismo, con menoscabo del juego intensivo de la existencia cotidiana. En realidad, «lo que ha sucedido es que la producción estética actual se ha integrado en la producción de mercancías en general: la frenética urgencia económica de producir constantemente nuevas oleadas refrescantes de géneros de apariencia cada vez más novedosa (desde los vestidos hasta los aviones), con cifras de negocios siempre crecientes, asigna una posición y una función estructural cada vez más fundamental a la innovación y la experimentación estética». Jameson, F., El posmodernismo o..., op. cit., p. 18. 
viduales, motorizadas por los designios del mercado con el pretexto de la autorrealización. En este contexto, la ética de la responsabilidad se diluye en beneficio de los non-binding commitments, cimentados sobre una impúdica concupiscencia que se arroga el derecho incuestionable a saborearlo todo ${ }^{35}$ pero, paradójicamente, emancipados de promesas y deberes grabados por la solidaridad, la lealtad o la reciprocidad, valores contraproducentes en un mundo donde, ante la inminente posibilidad del cambio, no cabe permitirse cargas existenciales. En definitiva, la transformación fundamental de nuestra psique se cifra en la liberación del egoísmo como autorreferencia de la naturaleza humana, esa actitud existencial de «ser-para-sí» (Für-sich-sein) condenada durante la era de la carencia y sus compensaciones holísticas, en perjuicio de la postura altruista o moral de «ser-para-otro». Entretanto, el «narcicismo de masa» consolida, con la infidelidad por bandera, el aislamiento de los individuos, privados de referentes afectivos por su deserción de la esfera pública y social ${ }^{36}$.

Con todo, los efectos morbosos de las operaciones de individuación contemporáneas no terminan en la atomización de la sociedad pues, con la inestabilidad (Unsicherheit) impregnando, por razón de los promiscuos mestizajes entre diversos «yoes», nuestro humus natural, y la relativa transformación de la experiencia de la temporalidad, las «patologías del criterio» adquieren una importancia inusitada en la vida del mercado. Primeramente, la inseguridad existencial erosiona sensiblemente tres tipos de confianza fundamentales en la «Modernidad sólida» (en nuestras aptitudes, en el otro y en las instituciones) ${ }^{37}$, por mor de lo cual el ámbito de las creencias que sustenta nuestra vida cotidiana se desvanece, toda vez convertidas en modas incapaces de proporcionar, por razón de su ingravidez, sistemas de referencias consistentes a la razón (más allá de la racionalidad reducida al cálculo de los medios, únicas necesidades patentes ante la desmesura pasional generalizada $)^{38}$. Pues bien, dado que los fundamentos débiles, basados en la veleidad del gusto personal, ocupan el ilustre asidero de los fundamentos monolíticos, antaño encarnados en figuras de lo necesario de diversa índole, nos volvemos incapaces de poner medida o establecer normas mínimas en la multiplicidad para realizar un balance, en detrimento de todo juicio y discernimiento.

35 La inclinación al consumo final del «último hombre» (el «Nihilismo», según la doctrina nietzscheana) conlleva, como refleja la etimología del verbo «consumir» («devorar, agotar, destruir»), una gran falta de respeto, dado que considera legítimo desechar sistemáticamente sus objetos de consumo. Consecuentemente, la transvaloración de todos los valores pretendida por Nietzsche termina siempre en desvalorización, de tal suerte que «tiene su modelo en el metabolismo orgánico. En la medida en que todo lo que es el caso está determinado a la ingestión por el consumidor, los desechos se convierten en el universal "resultado de la vida, a todos los niveles"». Sloterdijk, P., En el mundo..., op . cit., p. 251.

36 Bauman ofrece un testimonio imborrable sobre la sustitución de las relaciones sociales por conexiones efímeras y volátiles, por efecto de una socialización excesiva en los hábitos consumistas: $c f$. Bauman, Z., Amor líquido: Acerca de la fragilidad de los vínculos humanos, Madrid, FCE, 2005.

$37 C f$. Barroso, O., «Patologías del criterio en la era de la Globalización», en: L. Sáez y otros (eds.): Occidente enfermo. Filosofía y Patologías de Civilización, Múnich, Grin, 2011, pp. 93-113, pp. 107-8.

38 Con el objeto de salvar las circunstancias del yugo de la «razón pura», Ortega subraya el papel de las creencias en cualquier acto del pensar, ya sean ocurrencias vulgares o rigurosos razonamientos lógicos. Tanto los pensamientos originales como los insuflados brotan de una vida preexistente, mas toda existencia descansa, en cuanto «realidad ejecutiva», sobre unas creencias básicas. Por oposición a las ideas, no tenemos creencias como resultado de una faena del entendimiento sino que somos creencias, estamos en y contamos con ellas cuando pensamos en algo y, por ende, son ineludibles para tener o adoptar ideas (también las evidentes), que sólo poseen un valor virtual, como «hacer» no primario, en la vida real de lo que somos. Cf. Ortega y Gasset, J., Ideas y creencias, Madrid, Espasa-Calpe, 1964, pp. 17-36. 
Para mayor escarnio, aunque la antropología defiende con evidencias empíricas que la conciencia de ser un mismo individuo es una realidad prácticamente universal (pues infiere en funciones cerebrales como la coordinación de las percepciones o la concatenación de los estados anímicos), lo cierto es que la lógica devastadora del mercado impone, como revela la inagotable mutabilidad de las formas de vida, un régimen temporal de propulsión sin memoria por concurso del cual nuestra experiencia de la temporalidad queda totalmente trastocada, ya que nos instala en un presente perpetuo ${ }^{39}$ bajo soberanía sincrónica ${ }^{40}$. Y es que cuando el futuro irrumpe violentamente con novedades que no pueden integrarse en la experiencia heredada, la identidad se desvincula del pasado y se torna imposible aprender del recuerdo ${ }^{41}$, con menoscabo del vínculo, otrora inseparable, entre memoria y esperanza. Por consiguiente, dejamos de sentirnos impelidos a depositar nuestra fe (para desgracia de Sartre) en un proyet de la vie, pues las expectativas se desmarcan de nuestro horizonte de experiencia y, por tanto, no sabemos qué nos cabe esperar ${ }^{42}$. En resumen, la cadena de transmisión entre las generaciones se rompe y el tiempo dislocado se torna intempestivo, como una réplica primitiva de la rotación vertiginosa de la producción y el consumo universales.

Pues bien, si reparamos con atención en las dificultades actuales para elaborar juicios de valor atendiendo a criterios racionales, nos encontramos con que, en el intento desesperado por encontrar, sumidos en el espacio heteróclito del mercado, fuentes de arraigo existencial que el Capital se muestra incapaz de dispensar, existe el grave riesgo de resucitar viejos dioses modernos (el modelo colonial ilustrado, la nación como unidad de sangre,...), con sus terribles y ciegas repercusiones. Parafraseando a Marx, podríamos decir que el Capitalismo produce, también en la era post-industrial, sus propios sepultureros. A propósito de esta idea, cuando Arendt ilustra su tesis de la «banalidad del mal» con el caso Eichmann, nos alerta del peligro de que Auschwitz se repita, no tanto por pasiones sedimentadas a través de una

39 Cf. Jameson, F., Reflexiones sobre la postmodernidad: Una conversación de David Sánchez Usanos con Fredric Jameson, Madrid, Abada, 2010, pp. 126-7.

40 Cf. ib., pp. 67-8.

41 A ojos vistas, esta constatación puede resultar extraña si nos atenemos a la «tendencia memorialista» que marca lo que Nora designa como «era de la comunicación». $C f$. Nora, P., «Reasons for the current upsurge in memory», Transit-Europäische Revue, 22, 2002, pp. 1-9, p. 4. Hablamos de fenómenos como las revisiones críticas de la historia oficial y la recuperación de áreas históricas reprimidas, la reivindicación de pasados confiscados o suprimidos, el interés por la genealogía, la multiplicación de eventos conmemorativos y museos, la renovada sensibilidad por la conservación de archivos, el apego a legados patrimoniales e iniciativas que apelan por la memoria en nombre de la justicia, como la caída de dictaduras militares en América Latina y el fin del apartheid en Sudáfrica. $C f$. Mendlovic, B., «¿Hacia una "nueva época” en los estudios de memoria social?», Revista Mexicana de Ciencias Políticas y Sociales, 221, 2014, pp. 291-316, p. 294. Se trata, empero, de una invasión del pasado en el presente que, para nosotros, termina por convertir la memoria en simples recordatorios controlados en rituales, descafeinados, higienizados e inconexos, con el único significado de una efeméride.

42 Dado que el miedo radica en la incertidumbre, la metamorfosis de nuestra experiencia del tiempo fomenta la tendencia interna de la sociedad a la hiperfobia, esa sensación latente de hecatombe apremiante pero difusa, ampliada sistemáticamente por los mass media para colmar sus espurios intereses, que habita vagamente nuestra conciencia del porvenir. $C f$. Sanfélix, V., «Terror y globalización», en: R. Ávila y otros (eds.): Miradas a los otros. Dioses, destinos y civilizaciones, Madrid, Arena Libros, 2011, pp. 217-35, p. 223. A partir del planteamiento de Spinoza acerca del uso o abuso político del miedo, I. Hoyos analiza brillantemente dicho fenómeno y la correspondiente depresión inmunológica que sufrimos ante el riesgo en cuanto patología de civilización. $C f$. Hoyos, I., «Filosofía y patologías de civilización: libertad y miedo», en: Occidente enfermo..., op. cit., pp. 127-40, pp. 128-33. 
extensa tradición de antisemitismo, nacionalismo y esperas mesiánicas de revolución social, sino porque la obsesiva atención dispensada a los «mundos vitales» trastorna la «vida del espíritu», distorsionando nuestra facultad de juzgar, es decir, de distinguir entre el bien y el mal. De hecho, el sujeto en cuestión no era consciente de sus actos, que no responden a motivos ideológicos o patológicos (pese a su celo por exterminar judíos, no se trata, según sus propias declaraciones, de un antisemita fanático, ni presenta síntomas mórbidos evidentes), sino a una extraordinaria diligencia por progresar personalmente en pos de la cual se limita a obedecer las órdenes de sus superiores como un simple burócrata, sin percibir la crueldad de sus actos.

Ahora bien, si tomamos en serio los problemas derivados de la inseguridad existencial que presentamos más arriba, no podemos escapar al hecho de que los habitantes del mundosupermercado, esos «últimos hombres», están incapacitados para el dogmatismo, ya que su florecimiento sólo es posible cuando, en periodos históricos agitados, las creencias básicas son absolutizadas hasta confundirse con ideas inmutables y universales, concebidas como el único camino para la consecución de una meta determinada. Además, hace tiempo que el dinero se ha mostrado como alternativa operativamente exitosa. Pero como la experiencia de la «muerte de Dios» sigue confinada tras los márgenes de Occidente, cabe sospechar que, en aquellos pueblos cuyas posibilidades fundamentales de apropiación son negadas, el desarraigo puede traducirse en ira e indignación, de tal manera que, paradójicamente, las creencias sobre las cuales descansan crecerían hasta la atrofia y la cosificación, desencadenando un estallido de «Nihilismo» fanático (considerando el papel atenuante que debería jugar, a ojos de Benjamin, la memoria histórica, y el carácter irrelevante que de hecho posee, como consecuencia de la nueva noción de temporalidad que hemos señalado).

Independientemente de la conducta narcisista que favorecen, la muerte de arquetipos coherentes con los que entablar, con vistas a escapar a la espiral involutiva de los condicionamientos ajenos, una confrontación emancipatoria (lo que Freud denomina «superyó» bien estructurado) no ayuda, por lo demás, a paliar semejante amenaza, pues «la libertad se forja en una lucha contra la autoridad que tiene por objeto su interiorización y metabolización. (...) El que no ha luchado por la libertad no es libre» ${ }^{43}$. De hecho, si los regímenes totalitarios del siglo XX han sido generalmente asumidos sin ofrecer credenciales plausibles, es porque sin el reconocimiento estable de una legitimidad «vertical», brota ineluctablemente el deseo, recurrente en gran parte de la población, de más autoridad. Adorno rubrica nuestra perspectiva en sus observaciones sobre el declive de la familia, donde advierte que la transformación de la autoridad familiar en «un padre "gelatinoso", demasiado condescendiente o voluble, parecido a un muro de goma o un objeto insólito (como en el cuento de Kafka Odradek)» ${ }^{44}$ y la exaltación incondicional de un jefe político omnipotente (Caudillo, Duce, Führer) son fenómenos complementarios que manifiestan un desplazamiento de la necesidad de autoridad del ámbito familiar a la sociedad, de modo que los gobiernos autoritarios hunden sus raíces en el debilitamiento de los vínculos familiares sólidos, basados en una figura paterna percibida como fuerte pero justa, capaz de imponer prohibiciones y límites ${ }^{45}$.

43 Bodei, R., El doctor Freud y los nervios del alma. Filosofía y sociedad a un siglo del nacimiento del psicoanálisis, Valencia, Pre-Textos, 2004, p. 39.

$44 \mathrm{Ib}$.

45 Cf. ib., pp. 38-40. 
De tal suerte que el péndulo de la historia oscilaría, a expensas de los ideales del humanismo cosmopolita y sin fronteras, del narcicismo del «yo» a su inmersión en la morada del «nosotros», un «nosotros» pronto a renovar la barbarie del pasado, pero también a requerir que dimitamos de nuestra ilusión de autonomía, basada en la falsa conciencia de que existen posibilidades de elegir y salidas laterales por doquier. Se entienden ahora las controvertidas especulaciones de Jameson, en la línea de Baudrillard, Bauman o Žižek, acerca del 11-S, cuando mantiene que el fundamentalismo es esencialmente un fenómeno posmoderno ${ }^{46}$. Sólo desde este prisma, el famoso «conflicto entre civilizaciones» acuñado por Huntington representa, como revela la deriva tiránica del «nosotros» con el reciente apogeo del fanatismo religioso y sus sangrantes consecuencias globales, un reto mayor para el pensamiento contemporáneo.

46 Cf. Jameson, F., Reflexiones sobre la..., op. cit., pp. 93-7. 
